Received 6 January 2021

Accepted 13 July 2021

Link to DOI:

10.25220/WNJ.V04.i2.0009

Journal Website:

www.worldnutrijournal.org

\section{The effect of dietary fiber on insulin resistance in obesity: A literature review}

\author{
Santri D Faridahanum ${ }^{1}$, Fariz Nurwidya ${ }^{2}$, Yohannessa Wulandari ${ }^{1}$ \\ 1. Department of Nutrition, Faculty of Medicine, Universitas Indonesia-Dr. Cipto Mangunkusumo \\ General Hospital, Jakarta, Indonesia \\ 2. Department of Pulmonology and Respiratory Medicine, Faculty of Medicine, Universitas \\ Indonesia, Jakarta, Indonesia
}

\begin{abstract}
Introduction Obesity has become a significant public health problem in developing countries such as Indonesia. According to WHO, 13\% of adults aged 18 years and over were obese in 2016. In Indonesia, $21.8 \%$ of adults were obese. In obesity, the body's resistance to insulin will develop. Some studies showed a probable link between dietary fiber and insulin resistance. This research aims to investigate the role of the dietary fiber on insulin resistance in obesity.

Methods: This study is a literature study to determine the effect of dietary fiber on insulin resistance in obesity with sources from scientific publications 10 years back. The databases were PubMed and Google Scholar. The search term used was using the explode function for subgroup terms with operators ("and," or) for "dietary fiber", "obesity", "insulin resistance". Hand-searching was used to identify further potential eligible studies. There were no language restrictions, however only publications with full texts available were included. Total 138 publications titles and abstract were screened for their relevance to this literature review.

Results: A total of 25 publications were finally included. There are cross-sectional studies, randomized clinical trial, cohort studies, and article review. Some studies showed that dietary fiber had an effect on improve insulin resistance, but other studies did not find this effect.

Conclusion: The studies of dietary fiber effect on insulin resistance have inconsistent results. In the future, further studies are required for better understanding about the effect of dietary fiber on insulin resistance in obesity

Keywords dietary fiber, insulin resistance, obesity
\end{abstract}




\section{Methods}

\section{Introduction}

Obesity has become a significant public health problem in developing countries such as Indonesia. Worldwide, obesity has nearly tripled since 1975. According to WHO, $13 \%$ of adults aged 18 years and over were obese in $2016 .{ }^{1}$ In Indonesia, $21.8 \%$ of adults were obese. ${ }^{2}$ Obesity is an excessive accumulation of fat due to an imbalance in food intake and expenditure and can cause various health problems. Obesity is always associated with the level of fat or adipose tissue and chronic inflammation. In obesity, the body's resistance to insulin will develop. The development of insulin resistance is characterized by a reducing ability to take up glucose in fat and muscle. This disorder is a factor that underlies type 2 diabetes mellitus. The incidence of obesity can be influenced by various factors such as genetic, dietary pattern, and physical activity. ${ }^{3}$

Insulin resistance is a state of reduced sensitivity or tissue response to insulin so that glucose cannot enter and be used by cells. The impact of insulin resistance was type 2 diabetes and other health problems like obesity, hypertension, dyslipidemia, and metabolic syndrome. Assessment of insulin resistance was significant and aimed to prevent the further impact of insulin resistance. ${ }^{4}$

Various factors influence insulin resistance like eating habits, high fat and high carbohydrate diet, alcohol, and specific micronutrient deficiency. ${ }^{5}$ Besides that, lack of physical activity, stress, and lack of sleep are also contributing factors. ${ }^{6}$ Some studies showed a probable link between dietary fiber and insulin resistance. This study aimed to investigate the role of dietary fiber on insulin resistance in obesity. Several studies described the effect of dietary fiber and insulin resistance in various subjects with different results, but this article focused on the effect of dietary fiber on insulin resistance in obesity. This study also discussed information based on the most recent studies in the last 10 years.
This study is a literature review research that looked for theoretical references relevant to the cases or problems found. According to Creswell $^{7}$ stated that literature reviews are summaries of articles from journals, books, and other documents that describe theories and information both past and present and organize literature into the topics and the manuscripts needed. The type of data used by the author in this study is data obtained from literature studies. A literature study is a method used to collect data or sources related to the topic raised in a study. Data analyzed by the descriptive analysis method. The methods of descriptive analysis by describing the facts then followed by analyzing the facts, not merely a description, but also providing sufficient understanding and explanation. ${ }^{7}$

This study is a literature study to determine the effect of dietary fiber on insulin resistance in obesity with sources from scientific publications 10 years back. The databases were PubMed and Google Scholar. The search term used was using the explode function for subgroup terms with operators ("and," or) for "dietary fiber", obesity", "insulin resistance". Hand-searching was used to identify further potential eligible studies. There were no language restrictions, however only publications with full texts available were included. Total 138 publications titles and abstract were screened for their relevance to this literature review. Information extracted from each publication includes the study design, location, demographic characteristics of subjects, and dietary assessment method.

\section{Results}

After screening process, 25 publications were finally included. There are cross-sectional studies, cohort studies, randomized clinical trial, and article review. Some studies showed that dietary fiber had an effect on insulin resistance, but other studies did not find this effect. Some studies described several factors associated with insulin resistance. 


\section{Discussion}

\section{Insulin resistance in obesity}

Obesity-related insulin resistance is a complex disorder involving multiple pathway mechanisms. ${ }^{8}$ Although obesity is not always associated with insulin resistance, most people with insulin resistance are obese or overweight. Obesity is a fundamental risk factor for initiation and development of insulin resistance. ${ }^{9}$ Advances in molecular biology research have made better breakthroughs in finding much more to do with insulin resistance than just ten years ago. One mechanism for the signaling defects in obesity may be the increased expression and activity of several protein tyrosine phosphatases (PTPs), which dephosphorylate and thus terminate signaling propagated through tyrosyl phosphorylation. Some data indicated that at least three PTPs, including PTP1B, leukocyte antigen-related phosphatase (LAR), and src-homology-phosphatase 2 increased expression and / or activity in muscle and adipose tissue of obese humans and rodents. PTP1B and LAR showed to dephosphorylate the insulin receptor and IRS-1 in vitro. Mice in which PTP1B have increased insulin sensitivity and resistance to dietinduced obesity, at least in part, due to increased energy expenditure and suggests a regulatory role for PTP1B not only in insulin action but also in energy homeostasis. Interestingly, the insulin sensitivity is present in muscle and liver but not in adipocytes. There was a causal relationship between insulin sensitivity and leanness/energy expenditure or whether regulated by independent signaling pathways is a key question. ${ }^{8}$

Several mechanisms of which obesity causes insulin resistance are excess caloric intake (as commonly caused by a high-fat diet), adipose tissue dysfunction, oxidative stress, and inflammation at the tissue and systemic levels. ${ }^{8,9,10}$ Oxidative stress results from an imbalance of production of reactive oxygen species (ROS) and antioxidant defenses. Excess ROS will increase the inflammatory factors which directly interfere with insulin signaling in its target tissue. ${ }^{9}$

Obesity causes a chronic low-grade inflammation. During this process, immune cells infiltrate metabolic organs, especially WAT (white adipose tissue) and the liver, where they secrete proinflammatory cytokines which act locally and systemically after being released into the blood circulation. Pro-inflammatory cytokine levels in obesity is not as high as when infection occurred, however increases 2-3 times compared to homeostatic conditions. The most widely recognized pro-inflammatory cytokines in obesity are TNF $\alpha$ and IL-6. IL-7, CCL-2, etc also contribute in it. All of these inflammatory cytokines inhibit insulin signaling in different pathways. ${ }^{11}$ Hyperinsulinemia occurs in obesity and may be the cause of insulin resistance. Although it is commonly thought that hyperinsulinemia is resulted from insulin resistance, several studies suggest that high insulin level may lead to insulin resistance. Hyperinsulinemia in obesity is derived from overproduction of insulin or decreased clearance of insulin (Figure 1). Leptin resistance that occurs in obesity, may contribute to insulin overproduction in beta cells. Leptin inhibit insulin production in beta cell. Insulin clearance is carried out by the liver and kidneys. If there is malfunctioning of these two organs, then insulin clearance will decrease. ${ }^{8}$

Another mechanism for insulin resistance in obesity is based on genetic level. Increased global DNA methylation in obesity is positively correlated with insulin resistance. In obese people, there is an increased expression of the DNMT3a gene, which causes DNA methylation, either globally or locally, such as the main promoters of insulin pathway genes (INSR, SLC2A4). ${ }^{12}$

\section{Effect of dietary fiber on insulin resistance}

Fiber is a class of carbohydrates that cannot be digested by human digestive enzymes. Fiber categorizes in the group of complex carbohydrates and non-starch polysaccharides. The components of fibers classified into chemical properties like the ability of water solubility (soluble or insoluble fiber), the ability of fermented colonic microflora (fermentable vs non-fermentable fibers), or the viscosity (viscous vs non-viscous fibers). ${ }^{13}$

The fermentation bacteria of fiber in the large intestine produces short-chain fatty acids (SCFA), namely acetate, propionate, and butyrate. SCFAs play a significant role in the maintenance of health and disease progression. The highest levels of SCFA 
are found in the proximal colon, where they are either used locally by enterocytes or transported across the intestinal epithelium into the bloodstream. Two main SCFA signaling mechanisms identified as the inhibition of histone deacetylases (HDACs) and activation of G-protein-coupled receptors (GPCRs). Because HDAC regulates gene expression, HDAC inhibition has multiple consequences. ${ }^{14}$

SCFAs in the gut activate G-protein-coupled (GPR) receptors, such as GPR41 (i.e., free fatty acid receptor 3; FFAR3) and GPR43 (i.e., free fatty acid receptor 2; FFAR2). These receptors are present in ileum and colon enteroendocrine L-cells, adipocytes, and immune cells. Both GPR41 and GPR43 on intestinal epithelial L-cells trigger the secretion of intestinal hormones (GLP-1 and PYY). Leptin is also released from adipocytes when SCFA binds to GPR41. PYY, GLP1, and leptin can decrease appetite. GLP-1 increases insulin secretion from pancreatic $\beta$ cells and reduces glucagon secretion from the pancreatic islets, which leads to lower glucose production from the liver and increased peripheral glucose uptake. GLP1 can suppress appetite and food intake through the autonomic or central nervous system. ${ }^{15}$

SCFA will also stimulate PPAR $\gamma$ (Peroxisome Proliferator-Activated Receptor $\gamma$ ), where this activation will increase GLUT-4 in adipocytes.16 Activation of PPAR- $\gamma$ causes the release of adiponectin from mature adipocytes, which stimulates AMP involved in regulating GLUT4 in muscles, stimulating increased acid oxidation fat in the mitochondria, as well as downregulation of gluconeogenesis in the liver, which will lead to increased insulin sensitivity in muscles and the liver. ${ }^{15}$

Other mechanism of fiber reduces postprandial hyperglycemia by increasing satiety which results in weight loss. ${ }^{16}$ Soluble fiber slows gastric emptying and decreases absorption of macronutrients, causing a decrease in blood sugar and postprandial insulin levels because of the viscosity of the water-soluble fiber in the digestive tract. Different types of fiber have different effects on viscosity and absorption of nutrients. Guar gum is the most vicious type and has the best effect in lowering postprandial glucose. ${ }^{17}$

Insoluble fiber increases intestinal passage rate thereby decreasing absorption of nutrients, especially simple carbohydrates. This increased colonic transit which have a good impact on the gut microbiota which in turn increases the formation of SCFA. ${ }^{18}$

Several kinds of studies examining the relationship between dietary fiber and insulin resistance (Table 1). A cross-sectional study by Tucker et $\mathrm{al}^{23}$ involving 6374 subjects aged $20-84$ years, found that there is a significant relationship between HOMA IR and fiber intake in that group. There was also a negative and linear correlation between HOMA IR and fiber intake. It is explained that adults with high (Q4) fiber consumption significantly lower levels of insulin resistance (HOMA IR) than their counterparts (Q1-Q3). After controlling for differences in some demographic and lifestyle factors, and possible misreporting of energy intake, the inverse nutrients relationship between fiber intake and insulin resistance persisted.

Nevertheless, after adjusting for differences in abdominal obesity, there was no longer a relationship between fiber intake and insulin resistance. However, when participants divided into two groups based on whether or not they met the recommended fiber intake standard of $14 \mathrm{~g}$ per 1000 $\mathrm{kcal}$, insulin resistance differences were substantial and adjusting for differences in abdominal obesity no longer eliminated the relationship. Findings of the present investigation highlight the role of abdominal obesity in the association between fiber intake and insulin resistance, and the value of consuming at least $14 \mathrm{~g}$ of fiber per $1000 \mathrm{kcal}$ per day. Another study by Cuttler et $\mathrm{al}^{23}$ also found similar results. The study involved subjects with PCOS and non-PCOS who then measured their fiber intake and HOMA IR. There was a significant relationship between HOMA IR and fiber intake, and there was a negative correlation between fiber intake and HOMA IR. An RCT study by Gower et $\mathrm{al}^{21}$ also found similar results. This study involved 40 healthy female subjects aged $22-67$ years, nondiabetic, and had a normal BMI - obese. The subjects divided into two groups, namely the insulinsensitive group and the insulin-resistant group. Then given a resistant starch in the form of a snack with a dose of $15 \mathrm{~g} /$ day and $30 \mathrm{~g} /$ day for 4 weeks with a wash-out period of 4 weeks. At the end of the study, it was found that giving $30 \mathrm{gr} /$ day starch resistance could increase insulin sensitivity in the insulinresistant group. Meanwhile, in the insulin-sensitive 
group, the resistant starch did not affect insulin sensitivity.

In contrast to the results of the above studies, several studies obtained different results. Breneman et $\mathrm{al}^{19}$ conducted a study of 264 healthy, nonsmoking, and premenopausal women. The subjects were assessed for the fiber intake using a 7-day weighed food record, then divided into two groups, namely the high-fiber and low-fiber groups. The results of this study found that there was no significant difference from HOMA IR in the two subject groups. Another study by Ostrowska et $\mathrm{al}^{20}$ also obtained similar results. This study involved 143 subjects and divided into two groups based on HOMA IR levels, namely the study group (HOMA IR $>2$ ) and the control group (HOMA IR $<2$ ). The results showed that there was no significant difference in fiber consumption in the two groups. An RCT study by Roger et $\mathrm{al}^{24}$ assessed the effect of giving a whole-grain diet on insulin sensitivity. The study involved 60 adult subjects aged 20 - 65 years, with stable weight, BMI $25-35 \mathrm{~kg} / \mathrm{m} 2$, and/or increased waist circumference ( $\geq 94 \mathrm{~cm}$ for men and $\geq 80 \mathrm{~cm}$ for women). Subjects were given a whole grain diet and refined grain diet for 8 weeks with a wash-out period of 6 weeks. In the whole grain diet period, the mean fiber intake of the subjects increased and there was a significant difference with the mean fiber intake during the refined grain diet period. However, the administration of a whole grain diet did not alter insulin sensitivity but reduced body weight and systemic low-grade inflammation.

The study about fiber intake and insulin resistance showed different results. Many factors influence the differences in research results, for example, the age and gender of the subject. It is known that age and gender influence insulin resistance. Older age is associated with decreased insulin sensitivity due to an increase in adipocytes and decreased physical activity. ${ }^{25}$ Another possible mechanism is that chronic inflammation tends to increase with age. Chronic inflammation impairs neutral lipid accumulation, adipose tissue function, mitochondrial function, and causes stress to the endoplasmic reticulum which results in insulin resistance. ${ }^{26}$ Some studies only include female subjects, for example, the study of Brenneman, Cuttler, and Gower. There are differences in insulin sensitivity between men and women. The abundance of visceral and adipose tissue of the liver accompanied by low estrogen protective factors is associated with higher insulin resistance in men than in women. Estrogen is effective for increasing insulin sensitivity by a combination of many factors, such as directly affect insulin signaling in insulin sensitive tissue, releases of insulin from pancreatic beta cell, adipose tissue metabolism and energy expenditure, production of glucose from liver and regulates food intake from hypothalamus, and energy and metabolism. ${ }^{27}$

Other factors such as smoking status can influence the results of the study. Smoking is an independent risk factor for insulin resistance and type 2 diabetes. In the culture of muscle cell, nicotine exposure significantly increases phosphorylation of IRS-1ser636 and decreases insulin sensitivity. The two pathways known to stimulate phosphorylation of IRS-1ser636 (p44/42 mitogen-activated protein kinase [MAPK] and mammalian target of rapamycin [mTOR]) are both stimulated by nicotine. ${ }^{28}$ Nicotine also causes oxidative stress which in turn increases the expression of TNF $\alpha$ thereby activating mTOR. Smoking reduces insulin mediated glucose uptake by $10 \%-40 \%$ in men who smoke compared to men who do not smoke. ${ }^{29}$

Differences in the BMI and waist circumference of subjects in the study may also have influenced the results. BMI and waist circumference are associated with insulin resistance, where the mean HOMA IR results of subjects with normal nutritional status are lower than those with overnutrition and obesity. ${ }^{30}$

Another factor is the race differences of the previous studies. Genetics has an important role in the incidence of insulin resistance. Insulin resistance may occur in people with a family history of diabetes. Insulin resistance may also occur in certain ethnicities. In the US, black Americans and Pima Indians have a higher risk of insulin resistance than Caucasian Americans. In Asian countries, Indians and Chinese are also at high risk of developing insulin resistance. ${ }^{8}$

The assessment of the intake method also influences the results of the study. For example, Otruwska's study showed the assessment of intake used food recall. This method relies heavily on the subject's memory. It is easy to make mistakes when informing the food portions and affect the total 
amount of assessed intake. Weighed food records conducted in Brenneman's study can avoid recall bias and errors in determining food portions.

\section{Conclusion}

Dietary fiber is a significant component of the diet. Fiber has many functions in the body, one of which is to increase insulin sensitivity. In obesity, where insulin resistance will occur, fiber is expected to improve insulin sensitivity. The studies of dietary fiber effect on insulin resistance have inconsistent results. Some studies showed that dietary fiber had an effect on lowering insulin resistance, but other studies did not find this effect. Several factors affected this difference, such as gender, sex, genetic, smoking status, and physical activity. In the future, further studies are required for better understanding about the effect of dietary fiber on insulin resistance in obesity.

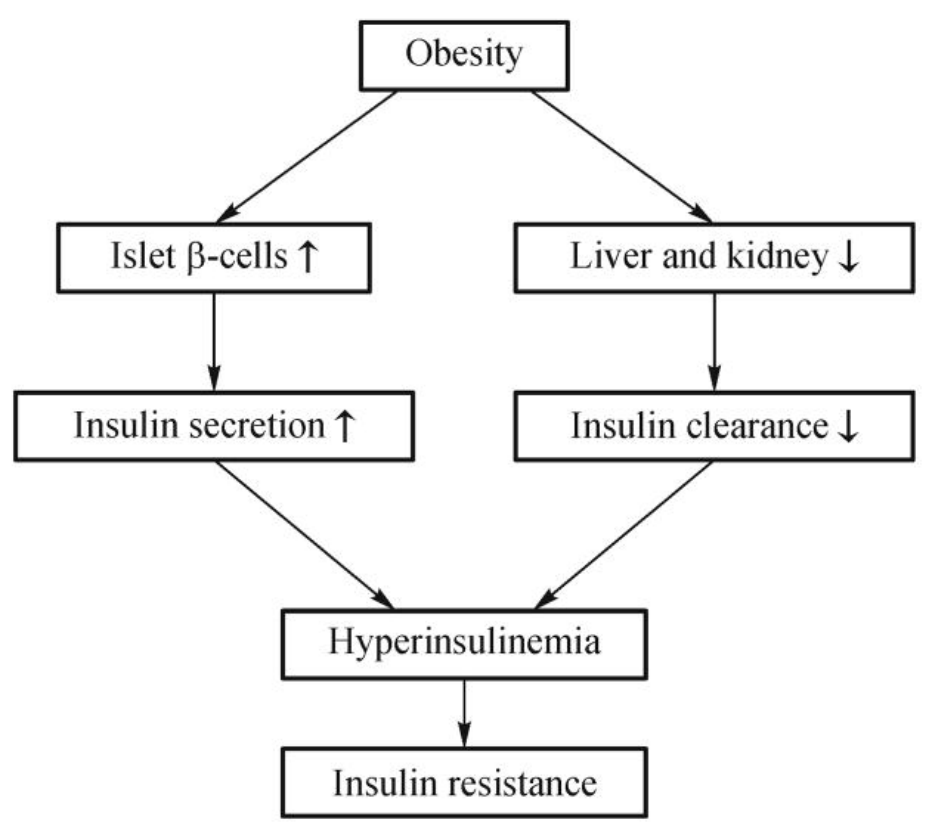

Figure 1. Hyperinsulinemia in obesity ${ }^{8}$ 
Table 1. Characteristics of the studies that examined dietary fiber and insulin resistance

\begin{tabular}{|c|c|c|c|}
\hline Author & Study Design & Subjects & Results/ Conclusion \\
\hline $\begin{array}{l}\text { Brenneman } \\
\text { CB, et al. } \\
\text { 2012 }^{19}\end{array}$ & Cross-sectional study & $\begin{array}{l}264 \text { healthy, non- } \\
\text { smoking, premenopausal } \\
\text { women }\end{array}$ & $\begin{array}{l}\text { No significant differences in HOMA IR } \\
\text { between groups with low and high total } \\
\text { fiber intake. }\end{array}$ \\
\hline $\begin{array}{l}\text { Ostrowska L, } \\
\text { et al. } \\
2013^{20}\end{array}$ & Cross sectional study & $\begin{array}{l}143 \text { subjects. } \\
\text { Study group (HOMA } \\
\text { IR }>2 \text { ) }=76 \text {, } \\
\text { Control group (HOMA } \\
\text { IR }<2)=67\end{array}$ & $\begin{array}{l}\text { No significant differences in the } \\
\text { consumption of fiber between groups. }\end{array}$ \\
\hline $\begin{array}{l}\text { Gower BA, et } \\
\text { al. } \\
2016^{21}\end{array}$ & $\begin{array}{l}\text { randomized, placebo- } \\
\text { controlled, double-blind, } \\
\text { cross-over study }\end{array}$ & $\begin{array}{l}40 \text { healthy, non-diabetic } \\
\text { women aged } 22-67 \text { years } \\
\text { in the normal-weight to } \\
\text { obese }\end{array}$ & $\begin{array}{l}\text { Consumption of Resistant Starch at a } \\
\text { dose of } 30 \mathrm{~g} / \mathrm{d} \text { in the form of a snack } \\
\text { food item was associated with } \\
\text { improved insulin sensitivity in insulin } \\
\text { resistant populations. It didn't affect } \\
\text { insulin sensitivity in insulin sensitive } \\
\text { populations. }\end{array}$ \\
\hline $\begin{array}{l}\text { Cutler DA, et } \\
\text { al. } \\
2018^{22}\end{array}$ & Cohort study & $\begin{array}{l}87 \text { PCOS women, } \\
50 \text { non-PCOS women }\end{array}$ & $\begin{array}{l}\text { There is significant differences in } \\
\text { HOMA IR between groups, fiber intake } \\
\text { was negatively correlated with HOMA- } \\
\text { IR. }\end{array}$ \\
\hline $\begin{array}{l}\text { Tucker. } \\
\text { 2018 }^{23}\end{array}$ & Cross-sectional study & 6374 adults, $20-84$ years & $\begin{array}{l}\text { There is significant differences in } \\
\text { HOMA IR between groups based on } \\
\text { quartile of fiber intake, fiber intake was } \\
\text { linearly and inversely related with } \\
\text { HOMA-IR. }\end{array}$ \\
\hline $\begin{array}{l}\text { Roager HM, } \\
\text { et al. } \\
2019^{24}\end{array}$ & $\begin{array}{l}\text { randomised cross-over } \\
\text { trial, two } 8 \text {-week dietary } \\
\text { intervention periods } \\
\text { comprising whole grain } \\
\text { diet and refined grain } \\
\text { diet, separated by a } \\
\text { washout period of } \geq 6 \\
\text { weeks. }\end{array}$ & $\begin{array}{l}60 \text { adults age } 20-65 \text { years } \\
\text { old and weight stable } \\
\text { with a body mass index of } \\
25-35 \mathrm{~kg} / \mathrm{m}^{2} \text { and } / \text { or } \\
\text { increased waist } \\
\text { circumference }(\geq 94 \mathrm{~cm} \\
\text { for men and } \geq 80 \mathrm{~cm} \text { for } \\
\text { women). }\end{array}$ & $\begin{array}{l}\text { Whole grain diet did not alter insulin } \\
\text { sensitivity but reduced body weight and } \\
\text { systemic low-grade inflammation. }\end{array}$ \\
\hline
\end{tabular}

\section{Conflict of Interest}

Authors declared no conflict of interest regarding this article.

\section{Open Access}

This article is distributed under the terms of the Creative Commons Attribution 4.0 International Licence

(http://creativecommons.org/licenses/by/4.0/), which permits unrestricted use, distribution, and reproduction in any medium, provided you give appropriate credit to the original author(s) and the source, provide a link to the Creative Commons license, and indicate if changes were made.

\section{References}

1. WHO. Obesity and overweight [Internet]. 2018 [cited April 2020]. Available from:https://www.who.int/newsroom/fact-sheets/detail/obesity-and-overweight).

2. Balitbangkes. Hasil Utama Riskesdas 2018. Jakarta; 2018.

3. Paleva, Rheza. Insulin Resistance Mechanisms Related to Obesity. Jurnal Ilmiah Kesehatan Sandi Husada. Vol 10, No, 2, Desember 2019, pp; 354-358.

4. Tan J, McKenzie C, Potamitis M, Thorburn AN, Mackay CR, Macia L, The Role of Short-Chain Fatty Acids in Health and Disease. 1st ed. Vol 121. Advances in Immunology. Elsevier Inc; 2014, 91-119 p. 
5. ołąbek KD, Regulska-Ilow B. Dietary support in insulin resistance: An overview of current scientific reports. Adv Clin Exp Med 2019;28(11):1577-1585.

6. Heikkilä HM, Krachler B, Rauramaa R, Schwab US. Diet, insulin secretion and insulin sensitivity - the Dose-Responses to Exercise Training (DR's EXTRA) Study (ISRCTN45977199). $\mathrm{Br}$ J Nutr 2014;112(9):1530- 1541.

7. Creswell, J. W. Qualitatif Inquiry and Research Design. California. Sage Publications, 2019.

8. Ye J. Mechanisms of insulin resistance in obesity. Front Med 2013;7(1):14-24.

9. Barazzoni R, Gortan Cappellari G, Ragni M, Nisoli E. Insulin resistance in obesity: an overview of fundamental alterations. Eat Weight Disord 2018;23(2):149-157.

10. Boden G. Obesity, insulin resistance and free fatty acids. Curr Opin Endocrinol Diabetes Obes 2011;18(2):139-143

11. Lauterbach MA, Wunderlich FT. Macrophage function in obesity-induced inflammation and insulin resistance. Pflugers Arch 2017;469(3-4):385-396. doi:10.1007/s00424-017-1955-5

12. Małodobra-Mazur M, Alama A, Bednarska-Chabowska D, Pawelka D, Myszczyszyn A, Dobosz T. Obesityinduced insulin resistance via changes in the DNA methylation profile of insulin pathway genes. Adv Clin Exp Med 2019;28(12):1599-1607.

13. Samuel, Varman T, Shulman GI. Integrating mechanisms for insulin resistance. Cell 2012;148(5):852-71.

14. Tan J, McKenzie C, Potamitis M, Thorburn AN, Mackay CR, Macia L. The Role of Short-Chain Fatty Acids in Health and Disease. 1st ed. Vol. 121, Advances in Immunology. Elsevier Inc.; 2014. 91-119 p.

15. Kim YA, Keogh JB, Clifton PM. Probiotics, prebiotics, synbiotics and insulin sensitivity. Nutr Res Rev 2017;117.

16. Post R, Mainous A, King D, Simpson K. Dietary fiber for the treatment of type 2 diabetes mellitus: a metaanalysis. J Am Board Fam Med 2012;25:16-23.

17. Feder D, Fonseca FLA. The Mechanism of Fiber Effects on Insulin Resistance. Dietary Fiber for the Prevention of Cardiovascular Disease. Elsevier Inc.; 2017. 23-33 p.

18. Muller M, Canfora, Blaak EE. Gastrointerstinal transite time, Glucose Homeostasis, and Metabolic Health: Modulation by Dietary Fibers. Nutrients 2018;10:275293.

19. Breneman CB. Dietary Fiber Consumption and Insulin Resistance: The Role of Body Fat and Physical Activity. BYU Sch Cit 2011;11-28.

20. Ostrowska L, Witczak K, Adamska E. Effect of Nutrition and Atherogenic Index on the Recurrence and Intensity of Insulin Resistance. Pol Arch Med Wewn 2013;123(6):289-96.

21. Gower BA, Bergman R, Stefanovski D, Darnell B, Ovalle F, Fisher G, et al. Baseline Insulin Sensitivity Affects Response To High-Amylose Maize Resistant
Starch In Women: A Randomized, Controlled Trial. Nutrition \& Metabolism 2016;13(2):1-8.

22. Cutler DA, Pride SM, Cheung AP. Low intakes of dietary fiber and magnesium are associated with insulin resistance and hyperandrogenism in polycystic ovary syndrome : A cohort study. Food Sci Nutr 2019;7:14261437.

23. Tucker LA. Fiber Intake and Insulin Resistance in 6374 Adults: The Role of Abdominal Obesity. Nutrients 2018 Feb 20;10(2):237.

24. Roager HM, Vogt JK, Hansen LB, et al. Whole GrainRich Diet Reduces Body Weight And Systemic LowGrade Inflammation Without Inducing Major Changes Of The Gut Microbiome: A Randomized Cross-Over Trial. Gut 2019;68:83-9.

25. Karakelides H, Irving BA, Short KR, O'Brien P, Sreekumaran Nair K. Age, obesity, and sex effects on insulin sensitivity and skeletal muscle mitochondrial function. Diabetes 2010;59(1):89-97.

26. Park MH, Kim DH, Lee EK, Kim ND, Im DS, Lee J, et al. Age-related inflammation and insulin resistance: A review of their intricate interdependency. Arch Pharm Res 2014;37(12):1507-14.

27. Gupte AA, Pownall HJ, Hamilton DJ. Estrogen: an emerging regulator of insulin action and mitochondrial function. J Diabetes Res. 2015;2015:916585.

28. Bergman BC, Perreault L, Hunerdosse D, et al. Novel and reversible mechanisms of smoking-induced insulin resistance in humans. Diabetes. 2012;61(12):31563166.

29. Śliwińska-Mossoń M, Milnerowicz H. The impact of smoking on the development of diabetes and its complications. Diab Vasc Dis Res 2017 Jul;14(4):265276.

30. Chen G, Liu C, Yao J, Jiang Q, Chen N, Huang H, Liang $\mathrm{J}$, Li L, Lin L. Overweight, obesity, and their associations with insulin resistance and $\beta$-cell function among Chinese: a cross-sectional study in China. Metabolism 2010 Dec 1;59(12):1823-32. 